\title{
Haemobilia from a ruptured hepatic pseudoaneurysm: a rare outcome of gangrenous cholecystitis.
}

\section{Elizabeth Lockie}

BBiomed, MD

Department of General Surgical Specialties, The Royal Melbourne Hospital, Australia Elizabeth.Lockie@mh.org.au

Benjamin Thomson

MBBS, FRACS

Department of General Surgical Specialties, The Royal Melbourne Hospital, Australia Benjamin.Thomson@mh.org.au

\section{Aaron Hui}

MBBS, FRACS

Department of General Surgical Specialties, The Royal Melbourne Hospital, Australia Aaronyshui@gmail.com

\section{Word count: 484}

\section{Figures: 3}

Tables: 0

The corresponding author is not the recipient of a research scholarship

\section{Corresponding author}

Elizabeth Lockie

Department of General Surgical Specialties

6 East

The Royal Melbourne Hospital

300 Grattan Street

Parkville

Victoria, Australia, 3050

Phone: +61393427000

Fax: +6139324 7802

This is the author manuscript accepted for publication and has undergone full peer review but has not been through the copyediting, typesetting, pagination and proofreading process, which may lead to differences between this version and the Version of Record. Please cite this article as doi: 10.1111/ans.15729

This article is protected by copyright. All rights reserved. 
Haemobilia from a ruptured hepatic pseudoaneurysm: a rare outcome of gangrenous cholecystitis.

Elizabeth Lockie

BBiomed, MD

Department of General Surgical Specialties, The Royal Melbourne Hospital, Australia

Elizabeth.Lockie@mh.org.au

Benjamin Thomson

MBBS, FRACS

Department of General Surgical Specialties, The Royal Melbourne Hospital, Australia

Benjamin.Thomson@mh.org.au

Aaron Hui

MBBS, FRACS

Department of General Surgical Specialties, The Royal Melbourne Hospital, Australia

Aaronyshui@gmail.com

Word count: 484

Figures: 3

Tables: 0

The corresponding author is not the recipient of a research scholarship

\section{Corresponding author}

Elizabeth Lockie

Department of General Surgical Specialties

6 East

The Royal Melbourne Hospital

300 Grattan Street

Parkville

Victoria, Australia, 3050

Phone: +61393427000

Fax: +6139324 7802 


\section{Haemobilia from a ruptured hepatic pseudoaneurysm: a rare outcome of gangrenous cholecystitis.}

\section{Case report}

A 31-year-old male from India presented to the emergency department after developing haematemesis and collapse in the waiting room of his general practitioner. He had presented two weeks prior with lethargy, weight loss and bloating. He was normotensive but tachycardic (110 beats/min). He had no abdominal tenderness and no signs of peritonism. His laboratory tests demonstrated obstructive liver function tests and a bilirubin of 153 . He proceeded to a CT-abdomen that showed a large hepatic artery pseudoaneurysm causing biliary obstruction, with intrahepatic bile duct dilatation and distension of the gallbladder (figure $1 \& 2$ ). The pseudoaneurysm was deemed too large for interventional radiological techniques, and thus he proceeded to to emergency theatre for open repair. En route to theatre the patient developed severe abdominal pain with a haemoglobin drop to 74 from 129.

Intraoperatively a large right hepatic artery pseudoaneurysm with rupture into the common bile duct was demonstrated, with a gangrenous gallbladder. Resection of the hepatic artery aneurysm required complete exclusion of the right hepatic artery. The bile duct defect was repaired primarily using 5.0 PDS and T-tube coverage. Intrabdominal drains were placed around the bile duct. 
Tubogram (figure 3) on day 13 post operation showed unobstructed distal flow in bile duct. He was discharged day 17 with T-tube in situ and planned reconstruction with a Roux-en-Y hepaticojejunostomy. Histopathology did not demonstrate a malignant cause for the aneurysm.

\section{Discussion}

Rupture of a hepatic arterial aneurysm into the biliary tree is a rare cause of haemobilia. It is most commonly a result of rupture of a pseudoaneurysm that has formed following biliary injury at cholecystectomy ${ }^{1}$, but can also form following major hepatic, biliary or pancreatic operations ${ }^{2}$, following blunt or penetrating trauma ${ }^{3}$, or rarely due to inflammatory processes ${ }^{4-7}$. Patients with a ruptured hepatic artery aneurysm usually present with right upper quadrant pain and jaundice and haemodynamic instability, or simply can have a transaminitis 8,9 .

Management of hepatic artery aneurysms includes interventional radiological procedures, such as embolization and stenting, as well as operative resection with or without vascular reconstruction ${ }^{2,8}$. In our case, the aneurysm and aneurysmal neck were deemed to be too large for interventional radiology. His subsequent haemodynamic collapse required emergent ligation of the hepatic artery inflow and right hepatic outflow for control. Repair of the eroded anterior 
wall of the common hepatic duct with the aneurysmal wall over a T-tube acted as a temporizing measure in an unstable patient.

Reconstruction of the bile duct by Hepp-Counaid Roux-en-Y hepaticojejunostomy was complicated by the loss of the hepatic artery. However the maintenance of continuity of the common bile duct as demonstrated on follow-up T-tubogram aided biliary repair.

Rupture of the hepatic arterial system into the biliary tree is a rare cause of haemobilia. It most commonly is a result of pseudoaneurysm rupture following biliary injury at cholecystectomy. We present a case of a ruptured mycotic pseudoaneurysm of the right hepatic artery secondary to gangrenous cholecystitis.

\section{References}

1. Green MH, Duell RM, Johnson CD, Jamieson NV. Haemobilia. Brit. J. Surg. 2001; 88: 773-786.

2. De Castro SM, Kuhlmann KF, Busch OR, van Delden OM, Laméris JS, van Gulik TM, Obertop H, Gouma D.. Delayed massive hemorrhage after pancreatic and biliary surgery: Embolization or surgery? Ann. Surg. 2005; 241:85-91.

This article is protected by copyright. All rights reserved. 
3. Coce MA, Fabian TC, Spiers JP, Kudsk KA. Traumatic hepatic artery pseudoaneurysm with hemobilia. Am. J. Surg. 1994; 168(3): 253-238.

4. Liu TT, Hou MC, Lin HC, Chang FY, Lee SD. Life-threatening hemobilia caused by hepatic artery pseudoaneurysm: a rare complication of chronic cholangitis. World J. Gastroenterol 2003; 9(12):2883-2884.

5. Akatsu T, Hayashi S, Egawa T, Doi M, Nagashima A, Kitano M, Yamane T, Yoshii H, Kitajima M. Hepatic artery pseudoaneurysm associated with cholecystitis that ruptured into the gallbladder. J. Gastroenterol. 2004; 39(9): 900-903.

6. Park SS, Kim BU, Han HS, Goo JC, Han JH, Bae IH, Park SM. Hemobilia from ruptured hepatic artery aneurysm in polyarteritis nodosa. Korean J. Intern. Med. 2006; 21(1): 79-82.

7. Kobayashi N, Kubota K, Nakajima A. Hepatic artery pseudoaneurysm associated with cholangitis that ruptured into the bile duct. Clin. Gastroenterol. Hepatol. 2009; 7(8): e45.

8. Erben Y, De Martino RR, Bjarnason H, Duncan AA, Kalra M, Oderich GS, Bower TC, Gloviczki P. Operative management of hepatic artery aneurysms. J. Vasc. Surg. 2015; 62(3): 610-615.

9. Winchester DP, Seed RW, Bergan JJ, Conn J. Jaundice, hemobilia, and hemoperitoneum. Consequences of rupture of hepatic artery aneurysm. Am. J. Surg. 1970: 120(3): 384-387. 


\section{Figures}

Figures 1 and 2. CT-abdomen demonstrating contrast extravasation into the common bile duct due to common hepatic artery aneurysm

Figure 3. Post-operative T-tubogram demonstrating an intact repair of the common bile duct with distal biliary drainage

This article is protected by copyright. All rights reserved. 


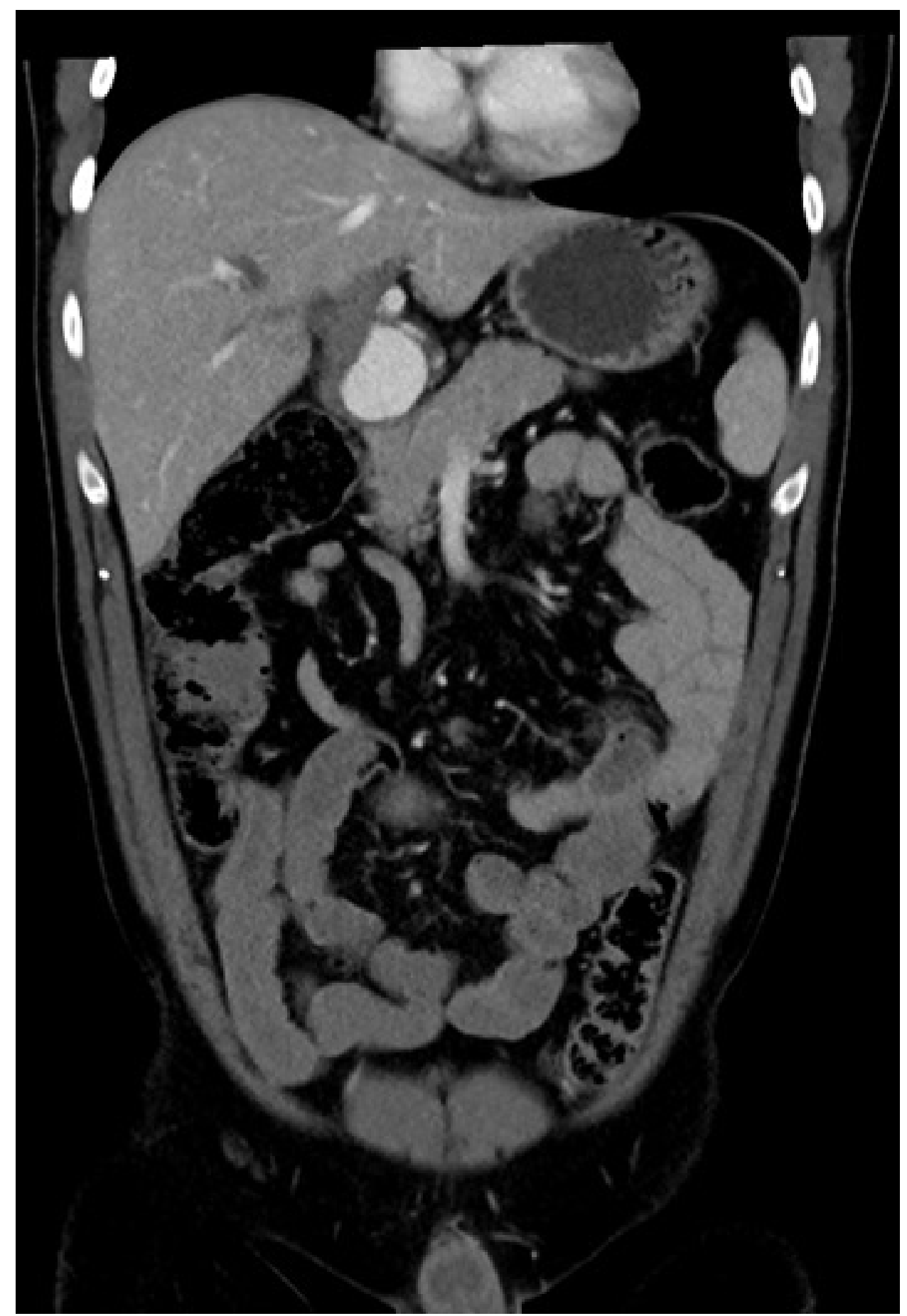

ANS_15729_Figure 1.tiff

This article is protected by copyright. All rights reserved. 


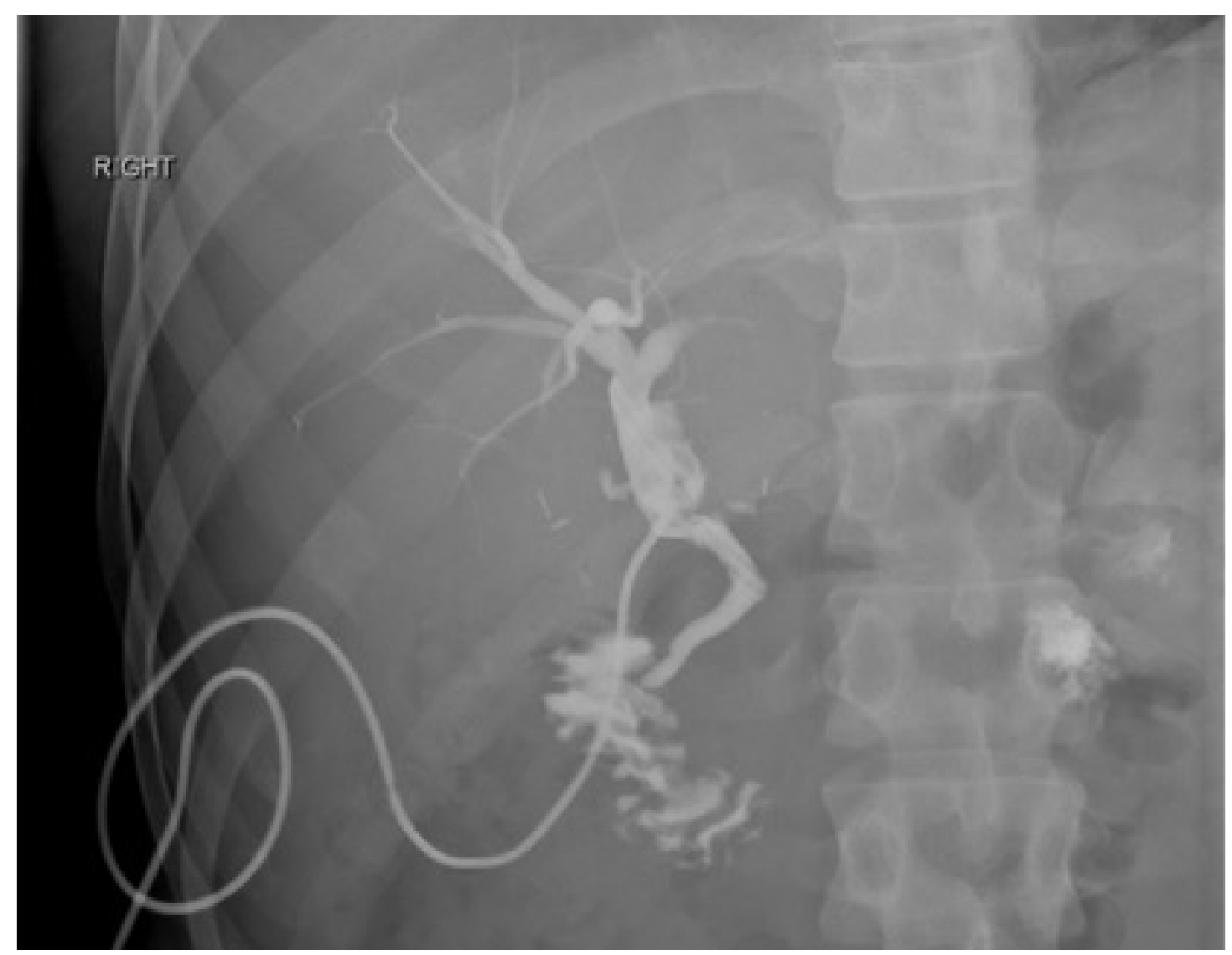

ANS_15729_Figure 3.tiff

This article is protected by copyright. All rights reserved. 


\section{University Library}

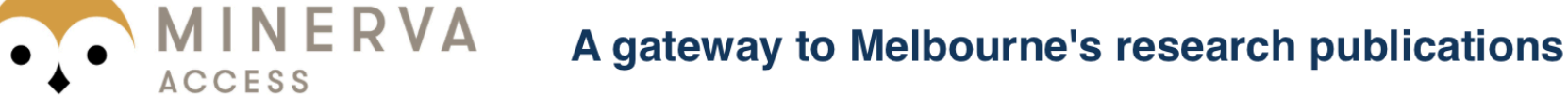

Minerva Access is the Institutional Repository of The University of Melbourne

Author/s:

Lockie, E;Hui, A;Thomson, B

Title:

Haemobilia from a ruptured hepatic pseudoaneurysm: a rare outcome of gangrenous cholecystitis

Date:

2020-02-13

Citation:

Lockie, E., Hui, A. \& Thomson, B. (2020). Haemobilia from a ruptured hepatic pseudoaneurysm: a rare outcome of gangrenous cholecystitis. ANZ JOURNAL OF SURGERY, 90 (10), pp.2119-2120. https://doi.org/10.1111/ans.15729.

Persistent Link:

http://hdl.handle.net/11343/275411 